\title{
Management of aseptic non union tibia using plating or interlocking nail with or without bone grafting
}

\author{
Meshneb M , Saleh A , Noaman H, Sheha A . \\ Orthopedics department ,Sohag university ,Sohag, Egypt
}

\begin{abstract}
Background : 'The purpose of this study is to compare results of usage of reamed interlocking nail versus plating in management of aseptic non- union fracture shaft tibia .Methods :20 patients with aseptic non union tibia were managed in our department between June 2015 and June 2016.Patients were divided randomlyin this retrospective study into two groups : plating group ( $\mathbf{1 0}$ patients ) and nailing group (10 patients ). Mean age of patients ( plating group ) was 40.3 years old, while in ( nailing group) was $\mathbf{3 0 . 3}$ years old. Illac bone graft was used in 4 patients (plating group ) and $\mathbf{3}$ patients (nailing group). Initial fracture was simple in $\mathbf{8}$ cases ( $\mathbf{4}$ in plating group and $\mathbf{4}$ in nailing group )and compound in $\mathbf{1 2}$ cases ( 6 in plating group and $\mathbf{6}$ in nailing group).Results :All patients were followed up in our patient clinic, with a mean period of follow up was 36.9 weeks. 19 cases healed and one case lost from( plating group). Mean period of healing was 6.7 months (plating group) while 4.7 months in (nailing group).According to Olerud and Molander score ,2 patients excellent , 2 good and $\mathbf{5}$ fair (plating group), while $\mathbf{1}$ patients excellent, $\mathbf{7}$ good and $\mathbf{2}$ fair (nailing group).No significant complications rate difference was found between the two groups . Conclusion:Reamed interlocking nail can obtain higher union rate, shorter time to union incidence and less complications rate than plating in the treatment of aseptic non union fracture shaft tibia.
\end{abstract}

\section{Introduction}

Non-union of tibial fractures is a relatively common problem and its incidence is higher than in other long bone fractures ${ }^{1}$.The incidence of tibialnon union is $\mathbf{2 - 1 0} \%$ of all tibialfracture, incidence is higher in high energy injuries and open fractures. The Weber-Cech ${ }^{2}$ classification is the one most widely used in this system. Most patients with this problem have been incapacitated for between six to twelve month ${ }^{3}$. Furthermore scarring from previous surgery and generalized osteopenia secondary to prolonged immobilization are important factors to be considered in further surgical management .Reamed intramedullary nailing offers the advantages of stable fixation, realignment of the intramedullary canal, and dynamic compression at the non-union site by early weight bearing. Success rates as high as $\mathbf{9 4 - 1 0 0 \%}$ have been reported in some series ${ }^{\mathbf{4 , 5}}$. However, generalized intramedullary osteomyelitis following reaming is the most worrying complication. Plating has the advantage of stable fixation in non union tibia where the fracture is distal or proximal .Soft fissue complications and metal failure are most common complications of plating. We conducted this study to compare the outcome of the reamed intra-medullary procedure and plating in aseptic nonunion tibia .

\section{Patients and Methods \\ Patients data}

Between June 2015 and June 2016, twenty consecutive patients with aseptic non-union of the fracture shaft tibia were treated in our orthopedic department in sohag medical school. Patients were divided by blind randomization in two groups : Ten patients were managed by plating, other ten patients were managed by reamed interlocking nail.Their average age was $\mathbf{3 3 . 7}$ years (range 17 to 65 years). There were thirteen males and seven females patients. The average follow-up was nine months (range between 7 to 18 months). The initial fracture was closed in eight patients( 4 patients in each group) and open in twelve patients ( 6 patients in each roup ). Five fractures were in the lower third area of the meta-diaphysealregion, the 
other ten were in the mid-shaft and five

fractures in proximal third fractures.

\begin{tabular}{|c|c|c|}
\hline Fracture level & $\begin{array}{c}\text { Number . of patients } \\
\text { With plate }\end{array}$ & $\begin{array}{c}\text { Number . of patients } \\
\text { With nail }\end{array}$ \\
\hline Proximal shaft & 4 & 1 \\
\hline Mid shaft & 3 & 7 \\
\hline Distal shaft & 3 & 10 \\
\hline Total & 10 & 2 \\
\hline
\end{tabular}

Table 1

The primary treatment had been with external fixator in four cases, plating in two ,plaster cast in three patients and interlocking nail in one patient. The patients had to undergo an average of two surgical procedures prior to non-union treatment. Seven patients underwentillac bone grafting for bone loss. There were thirteenatrophic ,fivethypertrophic nonunions and two pseudoarthrosis. The average interval between initial fracture and treatment of non-union was six months (range 3-14) months .

\section{Surgical procedure :}

The erythrocyte sedimentation rate and the C-reactive protein level were within normal limits in all patients prior to surgical intervention. Reamed intramedullary technique was attempted in ten cases. The proximal entry of the guide wire was performed through a patella tendon splitting incision. A non-ball tip guide wire was introduced until the nonunion area, and the fracture alignment was then confirmed by image intensifier. The reamer was carefully introduced to beyond the fibrous union, ensuring the disruption of the fibrous tissue to facilitate the further advancement of the guide wire. This procedure was a crucial part of the surgery to ensure the guide wire could be passed across non-union sites. Reaming of the intramedullary canal was performed in $\mathbf{0 . 5} \mathbf{m m}$ increments to the largest diameter.
The nails were locked distally and proximally with two screws for stability..

On the other hand, plating technique was done in other ten patients .Meticulous dissection was done at fracture site to protect soft tissue, good refreshing of bony edges was done and good alignment of bone with stable fixation was done by narrow locked in $\mathbf{3}$ patients and anatomical locked plate in 7 patients.

\section{Postoperative care ;}

Weight bearing in plating delayed up to six weeks .Touch weight bearing was allowed in 2 nd postoperative in nailing group then patients were encouraged to partial weight bear using crutches All patients in two groups were followed up by clinical examination included physical examination, neurovascular examination , assessment of axial alignment, and a functional analysis. Rotational alignment was assessed clinically by checking the relationship of the intercondylar axis with the intermalleolar axis and comparing with that of the normal side. Functional recovery was assessed using Olerud -Molanderankel score $^{6}$. Olerud - Molanderankel score of 91 to 100 points was considered excellent; 6190 points, good; 31-60 points, fair; and less than 31, poor.At every visit patients were examined using $\mathrm{x}$-ray to asses fracture union and clinically regarding knee and ankle function, walking ability, deformity and limb length discrepancy. 
SOHAG MEDICAL JOURNAL

Vol. 21 No.1 Jan 2017
Management of aseptic non union tibia using plating Mostafa Ali Khalifa

\section{Results}

Union was defined as radiological evidence of solid bridging callus formation and painless limb on full weight bearing. All non-union of tibial fractures healed at average of $\mathbf{6}$ months (range 3 - 12 months) except one patient lost. Table no 1 showing difference in healing incidence in the two groups . Average union time in nailing group was 4.7 months and $\mathbf{6 . 7}$ months in plating group . Eight cases with no complication ( nailing group ), One patient (nail group ) presented by mal rotation deformity ( $\mathbf{1 5}$ degree of external rotation of leg) andthe other case presented by superficial infection at site of distal locking screws and was managed by seialdebridment and locking screws removal. .On the other hand, Six cases with no complications ( plating group ) : Two cases ( plating group ) presented by superficial infection ( one was at site of plate, other at site of illac graft ). Both of them were managed by serial debridment and parentral antibiotics according to culuture and sensitivity. Plate exposure happened in one case. This case managed by local rotational flap .

\begin{tabular}{|r|c|c|}
\hline Union incidence & Number of patients With plate & Number of patients With nail \\
\hline$<6$ months & 4 & 6 \\
\hline $6-9$ months & 3 & 4 \\
\hline$>9$ months & 2 & 0 \\
\hline Total & 9 & 10 \\
\hline
\end{tabular}

Table 2

Three cases were excellent, nine cases were good and seven cases were fair according to Olerud and molander score (excellent more than 91 , good between $\mathbf{6 1}$ and 90 , fair between

$\mathbf{3 1}$ and $\mathbf{6 0}$ and poor less than $\mathbf{3 1}$ ). Table no $\mathbf{3}$ showing difference in two groups .

\begin{tabular}{|c|c|c|}
\hline $\begin{array}{c}\text { Olerud and } \\
\text { Molander score }\end{array}$ & $\begin{array}{c}\text { Number of patients } \\
\text { With plate }\end{array}$ & $\begin{array}{c}\text { Number of patients } \\
\text { With nail }\end{array}$ \\
\hline Excellent & 2 & 1 \\
\hline Good & 2 & 2 \\
\hline Fair & 5 & 0 \\
\hline Poor & 0 & 10 \\
\hline Total & 9 & \\
\hline
\end{tabular}

Table 3

\section{Discussion}

The main causes of long bone fracture eventuating in nonunion are instability of the fracture ends, insufficient bony contact and loss of blood supply ${ }^{7}$.Several surgical treatments have been advocated for the treatment of non union fracture tibia including compression plating, fibular osteotomy, cancellous bone graft, illazrof method and interlocking nail .The main cause of non union in this study is loss of blood supply as fourteen cases are atrophic non union .

Ten patients managed by plates, other ten patients managed by interlocking nail. Seven patients were managed by autogenusillacgrafting. Average follow up in this study was 9 months (range $\mathbf{7}$ to $\mathbf{1 8}$ months). Twenty patients achieved bone 
healing. Mean time of incidence of union was $\mathbf{6}$ months ( range between $\mathbf{3}$ to $\mathbf{1 2}$ months ).Ten patients achieved union in less than 6 months, seven patients between 6 - 9 months and three patients in more than 9 months. While in $\mathrm{CC} \mathrm{Wu}^{8}$ et al, all 31 patients were treated by reamed interlocking nailing. 28 patients were followed up for at least one year (range, 1.0-5.2 years; median, 2.2 years), while 3 were lost contact. All 28 tibialnonunions healed uneventfully, giving a $\mathbf{1 0 0 \%}$ union rate. The median union period was $\mathbf{4 . 5}$ months (range, 3.0-7.5 months). No extra cancellous bone graft was supplemented .While in WI Faisham ${ }^{9}$, et al, all twelve patients with aseptic non-union of the tibia were treated with the reamed interlocking technique..The average follow-up was eight months (range between $\mathbf{6}$ to $\mathbf{3 6}$ months). All non-union of tibial fractures healed at average of 16 weeks (range 12-30 weeks). Two patients underwent bone grafting for bone loss but failed to unite .In Galal Z. Said ${ }^{\mathbf{1 0}}$ et al, Thirty patients complaining of non union tibia were managed by plating (tibia profibula technique). Twenty two patients showed union at three months' follow-up. Of the remaining patients, four united in four months, and two united in six months. Two patients showing no radiological signs of healing at four months' follow-up were bone grafted, and united two months later. The mean healing time was $\mathbf{3 . 5}$ months. The duration of follow-up ranged between ten and 38 months (average 26 months).Grafting were done in $\mathbf{2 6}$ cases . In this study, average union time is $\mathbf{4 . 7}$ months ( nailing group), one case (nailing group ) is complicated by malrotation (15 degree external rotation), other case in this group complicated by infection at distal locking screw . So incidence of complications in this group is $20 \%$ .Whileaverage time of union was $\mathbf{6 . 7}$ months range between ( $\mathbf{3}-\mathbf{1 2}$ months ) ( plating group ). Two cases complicated by deep infection, serial debridment was done with culture and sensitivity test .
Other case complicated by plate exposure ,a local flap was done. Other one case complicated by infection at grafting site . So $\mathbf{4}$ cases ( $\mathbf{4 0} \%$ ) were complicated . So reamed interlocking nail give us best resuls and less complication rates . Interlocking intramedullary nailing with reaming offers the advantages of stable fixation, adequate alignment, minimum shortening, early weight bearing and high rate of union. Intramedullary nailing with reaming, however is not technically simple. The procedure requires the use of specialized instruments and techniques, including fluoroscopy image assistance. The risk with intramedullary nailing is the threat of infection, which is higher in cases with open fracture treated previously with external fixator and previous infection. Thorough evaluation before surgery and longer antibiotic cover in these cases will reduce the infection risk. While in Shih CH.et $\mathrm{al}^{\mathbf{1 1}}$, Among 105 tibial shaft aseptic nonunions followed for a mean of $\mathbf{3 2}$ months, 30 were treated with dynamic compression plating and $\mathbf{7 5}$ were treated with either Küntscher or Grosse-Kempf interlocking intramedullary nailing. With the plating technique, the union rate was $\mathbf{9 0 . 0 \%}(27 / 30)$, the period of time to union was $5.2+/-1.7$ months, the complication rate was $16.7 \%(5 / 30)$, the infection rate was $13.3 \%(4 / 30)$, and the surgical time was $110+/-30$ minutes. With the intramedullary nailing technique, the union rate was $93.3 \%(\mathbf{7 0 / 7 5})$, the period of time to union was $\mathbf{5 . 0}+/-\mathbf{1 . 6}$ months, the complication rate was $17.3 \%(\mathbf{1 3} / 75)$, the infection rate was $\mathbf{1 3 . 3 \%}(\mathbf{1 0 / 7 5})$, and the surgical time was $\mathbf{7 0}+/-\mathbf{3 0}$ minutes .While in Devnani AS et al ${ }^{\mathbf{1 2}}, \mathbf{2 5}$ patients with an average age of $\mathbf{3 5}$ years. The non-union involved $\mathbf{7}$ femurs, $\mathbf{8}$ humerii and $\mathbf{1 0}$ tibiae. The initial treatment was operative in 11 patients, by plaster cast in $\mathbf{5}$, by traction in $\mathbf{1}$ and by traditional practitioner in $\mathbf{8}$. The 25 case were treated by freshening the fracture ends, opening the medullary canal, re-aligning and stabilizing the fracture with a plate and packing autogenouscancellous 
bone grafts around the non-union site. All non-unions healed on an average in $\mathbf{1 8}$ weeks. There was neither incidence of

\section{Conclusion}

Reamed interlocking nail can be used in the management of asepticnon union tibia and give better results than plating technique. However nailingis technically requiring the availability of appropriate tools and surgical implants, Careful follow up of the patients is recommended. This technique confirmed by our results minimizes the complication rate and facilitates early return to normal activities of the patient.
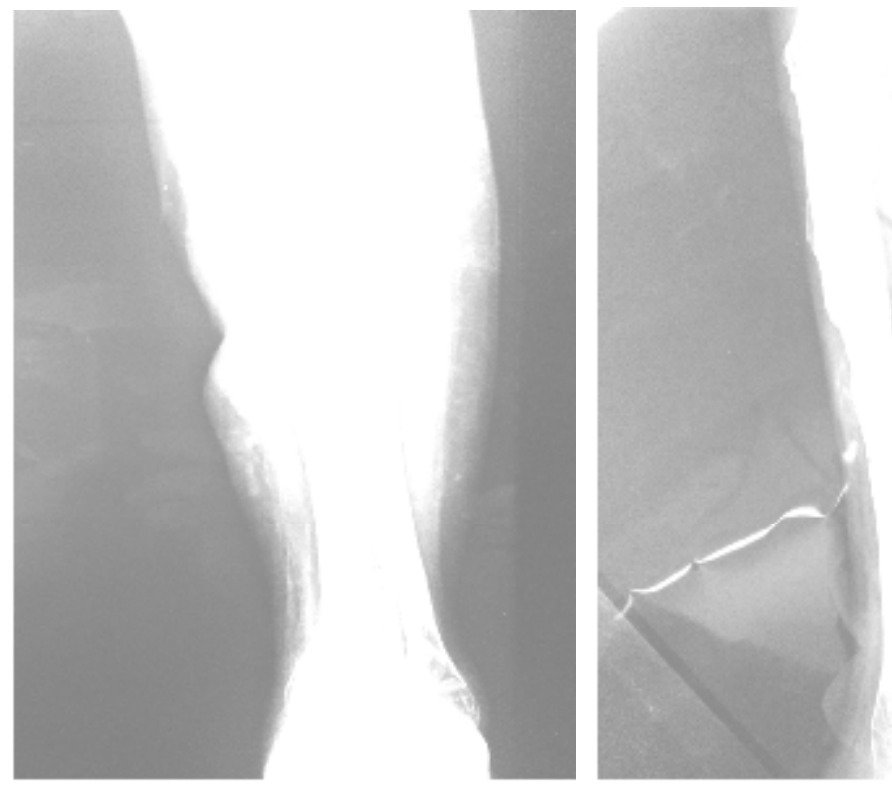

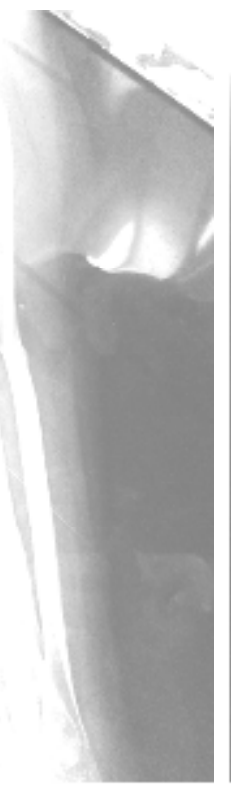

(B)

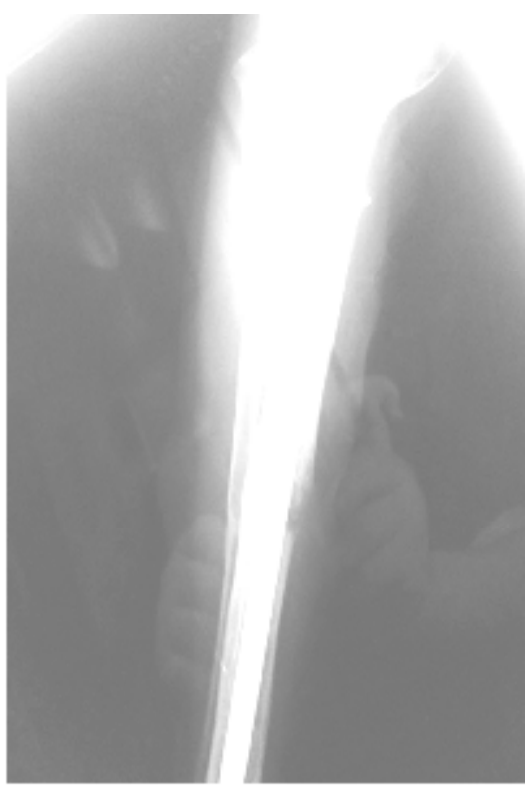

(C)

Male patient 18 years old presented by aseptic non union tibia managed by interlocking nail and grafting . ( A ) peroperative $\mathrm{x} \operatorname{ray}(\mathbf{B})$ six weeks follow up . ( C ) five months follow up . 


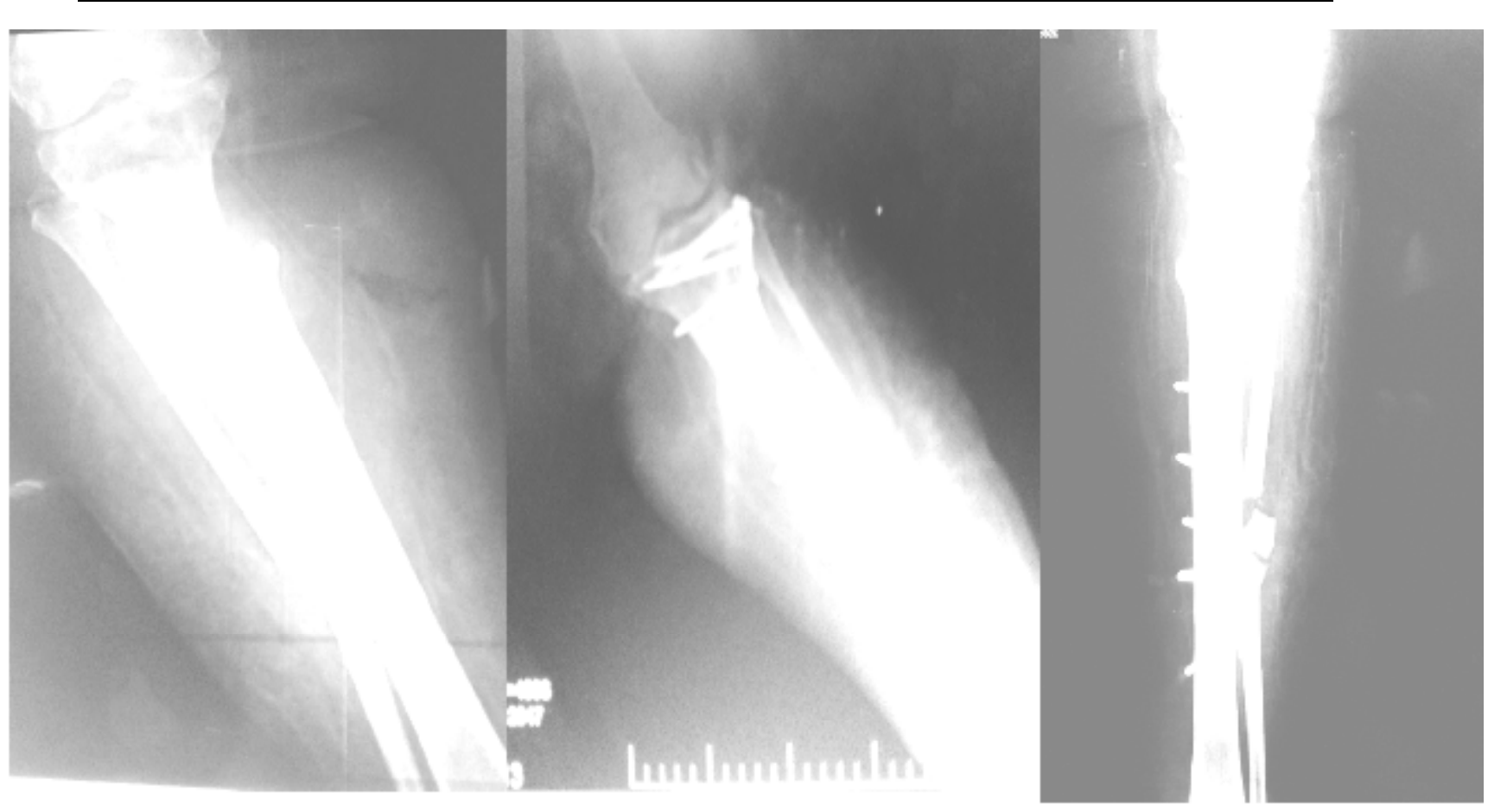

(A)

( B )

( C)

Female patient $\mathbf{5 5}$ years old presented by aspticnon union tibia managed by plating and grafting . (A) preoperative $\mathrm{x}$ ray . ( $\mathrm{B}$ ) postoperative $\mathrm{x}$ ray .

(C) five months follow up $x$ ray .

\section{References}

1. Boyd HB, Lipinsky SW, Willey JH. Observation on nonunion of the shafts of long bones with statistical analysis of $\mathbf{8 4 2}$ patients. J. Bone J. Surg. 1961; 43A: 159.

2- Weber, B.G.; Cech, O. Pseudarthrosis. Bern, Switzerland, Hans Huber, 1976.

3. Sledge SL, Johnson KD, Henley MB, Watson JT. Intramedullary nailing with reaming to treat nonunion oftibia. $\mathrm{J}$ Bone $\mathrm{J}$. Surg 1989; 71A: 1004.

4.Clancey GJ, Winquist RA, Hansen ST. Nonunion of the tibia treated with Kunt,cher intramedullary nailing. Clin.Orthop 1982; 167: 191.
5. Megas $\mathrm{P}$, Panagiotopoulos E, Skriviliotakis $\mathrm{S}$, Lambiris E. Intramedullary nailing in the treatment of

aseptic tibialnonunion. Injury 2001; 32: 23339.

6. OlerudC, Molander H. A scoring system for symptom evaluation after ankle fracture - Arch Orthop Trauma Surg. 1984;103:190-194.

7 .Weresh MJ, Hakanson R, Stover M, et al. Failure ofexchange reamed intramedullary nails for ununitedfemoral shaft fractures. $\mathbf{J}$ Orthop Trauma, 2000, 14: 335-338.

8- $\mathrm{CC} \mathrm{Wu}$. Reaming bone grafting to treat tibial shaft aseptic nonunion after plating . J Orthop Res 2003: 11(1): 16-21.

9- WI Faisham, MMed, A R Sulaiman ; et al . Early Outcome of Reamed Interlocking Nail for NonUnion of Tibia. Med $\mathbf{J}$ Malaysia Res 2006 Vol 61 No 3.

10.Galal Z. Said \& Mohammad M. ElSharkawi ; et al . Fibula-pro-tibia in plating 
SOHAG MEDICAL JOURNAL

Vol. 21 No.1 Jan 2017 tibial non-unions . J (SICOT) (2011) 35:1713-1718 .

11. Wu CC, Shih CH, Chen WJ, Tai CL. High success rate with exchanging to treat a tibial shaft aseptic non union .J Orthop Trauma 1999;13:33-8.
12.Devnani AS et; al. Simple approach to the management of aseptic non union of shaft of long bones. Singapore Med J 2001: 42 (1) :20-25. 


\title{
Management of aseptic non union tibia using plating or interlocking nail with or without bone grafting
}

\author{
Meshneb M , Saleh A , Noaman H, Sheha A . \\ Orthopedics department ,Sohag university ,Sohag, Egypt
}

\begin{abstract}
Background : 'The purpose of this study is to compare results of usage of reamed interlocking nail versus plating in management of aseptic non- union fracture shaft tibia .Methods :20 patients with aseptic non union tibia were managed in our department between June 2015 and June 2016.Patients were divided randomlyin this retrospective study into two groups : plating group ( $\mathbf{1 0}$ patients ) and nailing group (10 patients ). Mean age of patients ( plating group ) was 40.3 years old, while in ( nailing group) was $\mathbf{3 0 . 3}$ years old. Illac bone graft was used in 4 patients (plating group ) and $\mathbf{3}$ patients (nailing group). Initial fracture was simple in $\mathbf{8}$ cases ( $\mathbf{4}$ in plating group and $\mathbf{4}$ in nailing group )and compound in $\mathbf{1 2}$ cases ( 6 in plating group and $\mathbf{6}$ in nailing group).Results :All patients were followed up in our patient clinic, with a mean period of follow up was 36.9 weeks. 19 cases healed and one case lost from( plating group). Mean period of healing was 6.7 months (plating group) while 4.7 months in (nailing group).According to Olerud and Molander score ,2 patients excellent , 2 good and $\mathbf{5}$ fair (plating group), while $\mathbf{1}$ patients excellent, $\mathbf{7}$ good and $\mathbf{2}$ fair (nailing group).No significant complications rate difference was found between the two groups . Conclusion:Reamed interlocking nail can obtain higher union rate, shorter time to union incidence and less complications rate than plating in the treatment of aseptic non union fracture shaft tibia.
\end{abstract}

\section{Introduction}

Non-union of tibial fractures is a relatively common problem and its incidence is higher than in other long bone fractures ${ }^{1}$.The incidence of tibialnon union is $\mathbf{2 - 1 0} \%$ of all tibialfracture, incidence is higher in high energy injuries and open fractures. The Weber-Cech ${ }^{2}$ classification is the one most widely used in this system. Most patients with this problem have been incapacitated for between six to twelve month ${ }^{3}$. Furthermore scarring from previous surgery and generalized osteopenia secondary to prolonged immobilization are important factors to be considered in further surgical management .Reamed intramedullary nailing offers the advantages of stable fixation, realignment of the intramedullary canal, and dynamic compression at the non-union site by early weight bearing. Success rates as high as $\mathbf{9 4 - 1 0 0 \%}$ have been reported in some series ${ }^{\mathbf{4 , 5}}$. However, generalized intramedullary osteomyelitis following reaming is the most worrying complication. Plating has the advantage of stable fixation in non union tibia where the fracture is distal or proximal .Soft fissue complications and metal failure are most common complications of plating. We conducted this study to compare the outcome of the reamed intra-medullary procedure and plating in aseptic nonunion tibia .

\section{Patients and Methods \\ Patients data}

Between June 2015 and June 2016, twenty consecutive patients with aseptic non-union of the fracture shaft tibia were treated in our orthopedic department in sohag medical school. Patients were divided by blind randomization in two groups : Ten patients were managed by plating, other ten patients were managed by reamed interlocking nail.Their average age was $\mathbf{3 3 . 7}$ years (range 17 to 65 years). There were thirteen males and seven females patients. The average follow-up was nine months (range between 7 to 18 months). The initial fracture was closed in eight patients( 4 patients in each group) and open in twelve patients ( 6 patients in each roup ). Five fractures were in the lower third area of the meta-diaphysealregion, the 
other ten were in the mid-shaft and five

fractures in proximal third fractures.

\begin{tabular}{|c|c|c|}
\hline Fracture level & $\begin{array}{c}\text { Number . of patients } \\
\text { With plate }\end{array}$ & $\begin{array}{c}\text { Number . of patients } \\
\text { With nail }\end{array}$ \\
\hline Proximal shaft & 4 & 1 \\
\hline Mid shaft & 3 & 7 \\
\hline Distal shaft & 3 & 10 \\
\hline Total & 10 & 2 \\
\hline
\end{tabular}

Table 1

The primary treatment had been with external fixator in four cases, plating in two ,plaster cast in three patients and interlocking nail in one patient. The patients had to undergo an average of two surgical procedures prior to non-union treatment. Seven patients underwentillac bone grafting for bone loss. There were thirteenatrophic ,fivethypertrophic nonunions and two pseudoarthrosis. The average interval between initial fracture and treatment of non-union was six months (range 3-14) months .

\section{Surgical procedure :}

The erythrocyte sedimentation rate and the C-reactive protein level were within normal limits in all patients prior to surgical intervention. Reamed intramedullary technique was attempted in ten cases. The proximal entry of the guide wire was performed through a patella tendon splitting incision. A non-ball tip guide wire was introduced until the nonunion area, and the fracture alignment was then confirmed by image intensifier. The reamer was carefully introduced to beyond the fibrous union, ensuring the disruption of the fibrous tissue to facilitate the further advancement of the guide wire. This procedure was a crucial part of the surgery to ensure the guide wire could be passed across non-union sites. Reaming of the intramedullary canal was performed in $\mathbf{0 . 5} \mathbf{m m}$ increments to the largest diameter.
The nails were locked distally and proximally with two screws for stability..

On the other hand, plating technique was done in other ten patients .Meticulous dissection was done at fracture site to protect soft tissue, good refreshing of bony edges was done and good alignment of bone with stable fixation was done by narrow locked in $\mathbf{3}$ patients and anatomical locked plate in 7 patients.

\section{Postoperative care ;}

Weight bearing in plating delayed up to six weeks .Touch weight bearing was allowed in 2 nd postoperative in nailing group then patients were encouraged to partial weight bear using crutches All patients in two groups were followed up by clinical examination included physical examination, neurovascular examination , assessment of axial alignment, and a functional analysis. Rotational alignment was assessed clinically by checking the relationship of the intercondylar axis with the intermalleolar axis and comparing with that of the normal side. Functional recovery was assessed using Olerud -Molanderankel score $^{6}$. Olerud - Molanderankel score of 91 to 100 points was considered excellent; 6190 points, good; 31-60 points, fair; and less than 31, poor.At every visit patients were examined using $\mathrm{x}$-ray to asses fracture union and clinically regarding knee and ankle function, walking ability, deformity and limb length discrepancy. 
SOHAG MEDICAL JOURNAL

Vol. 21 No.1 Jan 2017
Management of aseptic non union tibia using plating Mostafa Ali Khalifa

\section{Results}

Union was defined as radiological evidence of solid bridging callus formation and painless limb on full weight bearing. All non-union of tibial fractures healed at average of $\mathbf{6}$ months (range 3 - 12 months) except one patient lost. Table no 1 showing difference in healing incidence in the two groups . Average union time in nailing group was 4.7 months and $\mathbf{6 . 7}$ months in plating group . Eight cases with no complication ( nailing group ), One patient (nail group ) presented by mal rotation deformity ( $\mathbf{1 5}$ degree of external rotation of leg) andthe other case presented by superficial infection at site of distal locking screws and was managed by seialdebridment and locking screws removal. .On the other hand, Six cases with no complications ( plating group ) : Two cases ( plating group ) presented by superficial infection ( one was at site of plate, other at site of illac graft ). Both of them were managed by serial debridment and parentral antibiotics according to culuture and sensitivity. Plate exposure happened in one case. This case managed by local rotational flap .

\begin{tabular}{|r|c|c|}
\hline Union incidence & Number of patients With plate & Number of patients With nail \\
\hline$<6$ months & 4 & 6 \\
\hline $6-9$ months & 3 & 4 \\
\hline$>9$ months & 2 & 0 \\
\hline Total & 9 & 10 \\
\hline
\end{tabular}

Table 2

Three cases were excellent, nine cases were good and seven cases were fair according to Olerud and molander score (excellent more than 91 , good between $\mathbf{6 1}$ and 90 , fair between

$\mathbf{3 1}$ and $\mathbf{6 0}$ and poor less than $\mathbf{3 1}$ ). Table no $\mathbf{3}$ showing difference in two groups .

\begin{tabular}{|c|c|c|}
\hline $\begin{array}{c}\text { Olerud and } \\
\text { Molander score }\end{array}$ & $\begin{array}{c}\text { Number of patients } \\
\text { With plate }\end{array}$ & $\begin{array}{c}\text { Number of patients } \\
\text { With nail }\end{array}$ \\
\hline Excellent & 2 & 1 \\
\hline Good & 2 & 2 \\
\hline Fair & 5 & 0 \\
\hline Poor & 0 & 10 \\
\hline Total & 9 & \\
\hline
\end{tabular}

Table 3

\section{Discussion}

The main causes of long bone fracture eventuating in nonunion are instability of the fracture ends, insufficient bony contact and loss of blood supply ${ }^{7}$.Several surgical treatments have been advocated for the treatment of non union fracture tibia including compression plating, fibular osteotomy, cancellous bone graft, illazrof method and interlocking nail .The main cause of non union in this study is loss of blood supply as fourteen cases are atrophic non union .

Ten patients managed by plates, other ten patients managed by interlocking nail. Seven patients were managed by autogenusillacgrafting. Average follow up in this study was 9 months (range $\mathbf{7}$ to $\mathbf{1 8}$ months). Twenty patients achieved bone 
healing. Mean time of incidence of union was $\mathbf{6}$ months ( range between $\mathbf{3}$ to $\mathbf{1 2}$ months ).Ten patients achieved union in less than 6 months, seven patients between 6 - 9 months and three patients in more than 9 months. While in $\mathrm{CC} \mathrm{Wu}^{8}$ et al, all 31 patients were treated by reamed interlocking nailing. 28 patients were followed up for at least one year (range, 1.0-5.2 years; median, 2.2 years), while 3 were lost contact. All 28 tibialnonunions healed uneventfully, giving a $\mathbf{1 0 0 \%}$ union rate. The median union period was $\mathbf{4 . 5}$ months (range, 3.0-7.5 months). No extra cancellous bone graft was supplemented .While in WI Faisham ${ }^{9}$, et al, all twelve patients with aseptic non-union of the tibia were treated with the reamed interlocking technique..The average follow-up was eight months (range between $\mathbf{6}$ to $\mathbf{3 6}$ months). All non-union of tibial fractures healed at average of 16 weeks (range 12-30 weeks). Two patients underwent bone grafting for bone loss but failed to unite .In Galal Z. Said ${ }^{\mathbf{1 0}}$ et al, Thirty patients complaining of non union tibia were managed by plating (tibia profibula technique). Twenty two patients showed union at three months' follow-up. Of the remaining patients, four united in four months, and two united in six months. Two patients showing no radiological signs of healing at four months' follow-up were bone grafted, and united two months later. The mean healing time was $\mathbf{3 . 5}$ months. The duration of follow-up ranged between ten and 38 months (average 26 months).Grafting were done in $\mathbf{2 6}$ cases . In this study, average union time is $\mathbf{4 . 7}$ months ( nailing group), one case (nailing group ) is complicated by malrotation (15 degree external rotation), other case in this group complicated by infection at distal locking screw . So incidence of complications in this group is $20 \%$ .Whileaverage time of union was $\mathbf{6 . 7}$ months range between ( $\mathbf{3}-\mathbf{1 2}$ months ) ( plating group ). Two cases complicated by deep infection, serial debridment was done with culture and sensitivity test .
Other case complicated by plate exposure ,a local flap was done. Other one case complicated by infection at grafting site . So $\mathbf{4}$ cases ( $\mathbf{4 0} \%$ ) were complicated . So reamed interlocking nail give us best resuls and less complication rates . Interlocking intramedullary nailing with reaming offers the advantages of stable fixation, adequate alignment, minimum shortening, early weight bearing and high rate of union. Intramedullary nailing with reaming, however is not technically simple. The procedure requires the use of specialized instruments and techniques, including fluoroscopy image assistance. The risk with intramedullary nailing is the threat of infection, which is higher in cases with open fracture treated previously with external fixator and previous infection. Thorough evaluation before surgery and longer antibiotic cover in these cases will reduce the infection risk. While in Shih CH.et $\mathrm{al}^{\mathbf{1 1}}$, Among 105 tibial shaft aseptic nonunions followed for a mean of $\mathbf{3 2}$ months, 30 were treated with dynamic compression plating and $\mathbf{7 5}$ were treated with either Küntscher or Grosse-Kempf interlocking intramedullary nailing. With the plating technique, the union rate was $\mathbf{9 0 . 0 \%}(27 / 30)$, the period of time to union was $5.2+/-1.7$ months, the complication rate was $16.7 \%(5 / 30)$, the infection rate was $13.3 \%(4 / 30)$, and the surgical time was $110+/-30$ minutes. With the intramedullary nailing technique, the union rate was $93.3 \%(\mathbf{7 0 / 7 5})$, the period of time to union was $\mathbf{5 . 0}+/-\mathbf{1 . 6}$ months, the complication rate was $17.3 \%(\mathbf{1 3} / 75)$, the infection rate was $\mathbf{1 3 . 3 \%}(\mathbf{1 0 / 7 5})$, and the surgical time was $\mathbf{7 0}+/-\mathbf{3 0}$ minutes .While in Devnani AS et al ${ }^{\mathbf{1 2}}, \mathbf{2 5}$ patients with an average age of $\mathbf{3 5}$ years. The non-union involved $\mathbf{7}$ femurs, $\mathbf{8}$ humerii and $\mathbf{1 0}$ tibiae. The initial treatment was operative in 11 patients, by plaster cast in $\mathbf{5}$, by traction in $\mathbf{1}$ and by traditional practitioner in $\mathbf{8}$. The 25 case were treated by freshening the fracture ends, opening the medullary canal, re-aligning and stabilizing the fracture with a plate and packing autogenouscancellous 
bone grafts around the non-union site. All non-unions healed on an average in $\mathbf{1 8}$ weeks. There was neither incidence of

\section{Conclusion}

Reamed interlocking nail can be used in the management of asepticnon union tibia and give better results than plating technique. However nailingis technically requiring the availability of appropriate tools and surgical implants, Careful follow up of the patients is recommended. This technique confirmed by our results minimizes the complication rate and facilitates early return to normal activities of the patient.
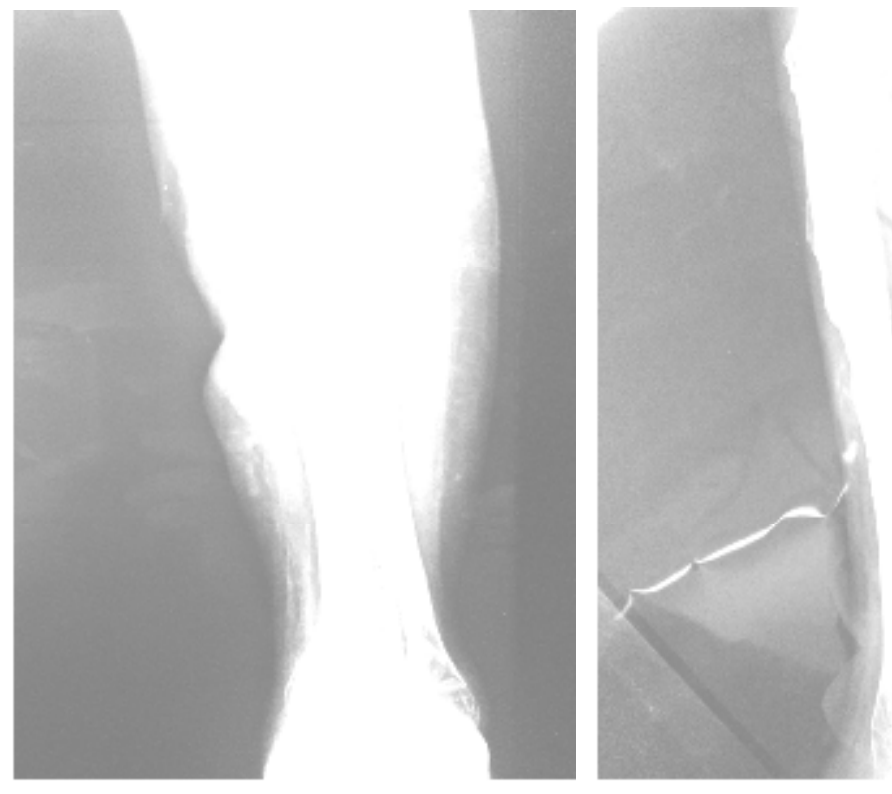

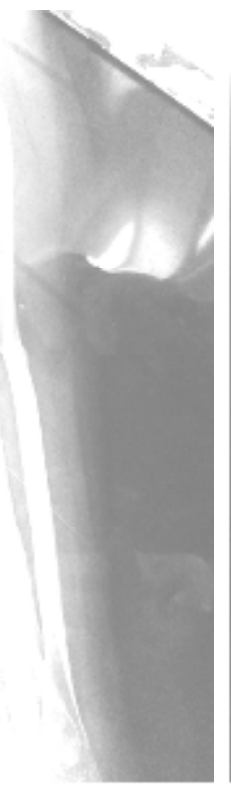

(B)

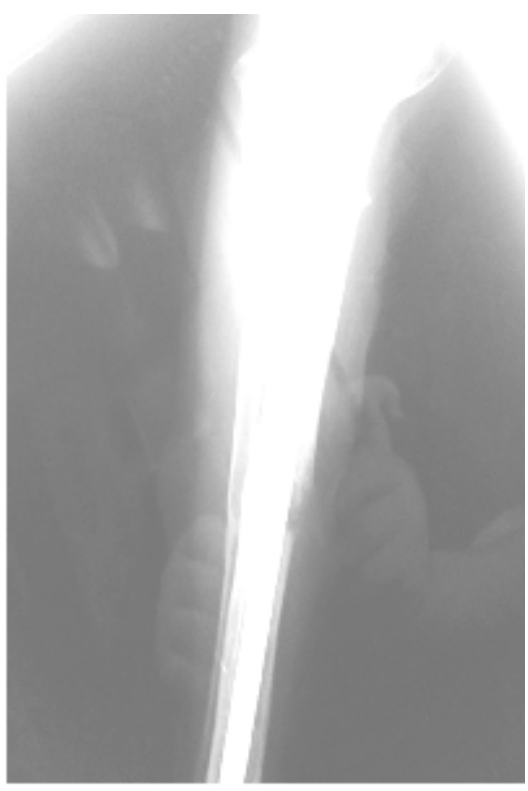

(C)

Male patient 18 years old presented by aseptic non union tibia managed by interlocking nail and grafting . ( A ) peroperative $\mathrm{x} \operatorname{ray}(\mathbf{B})$ six weeks follow up . ( C ) five months follow up . 


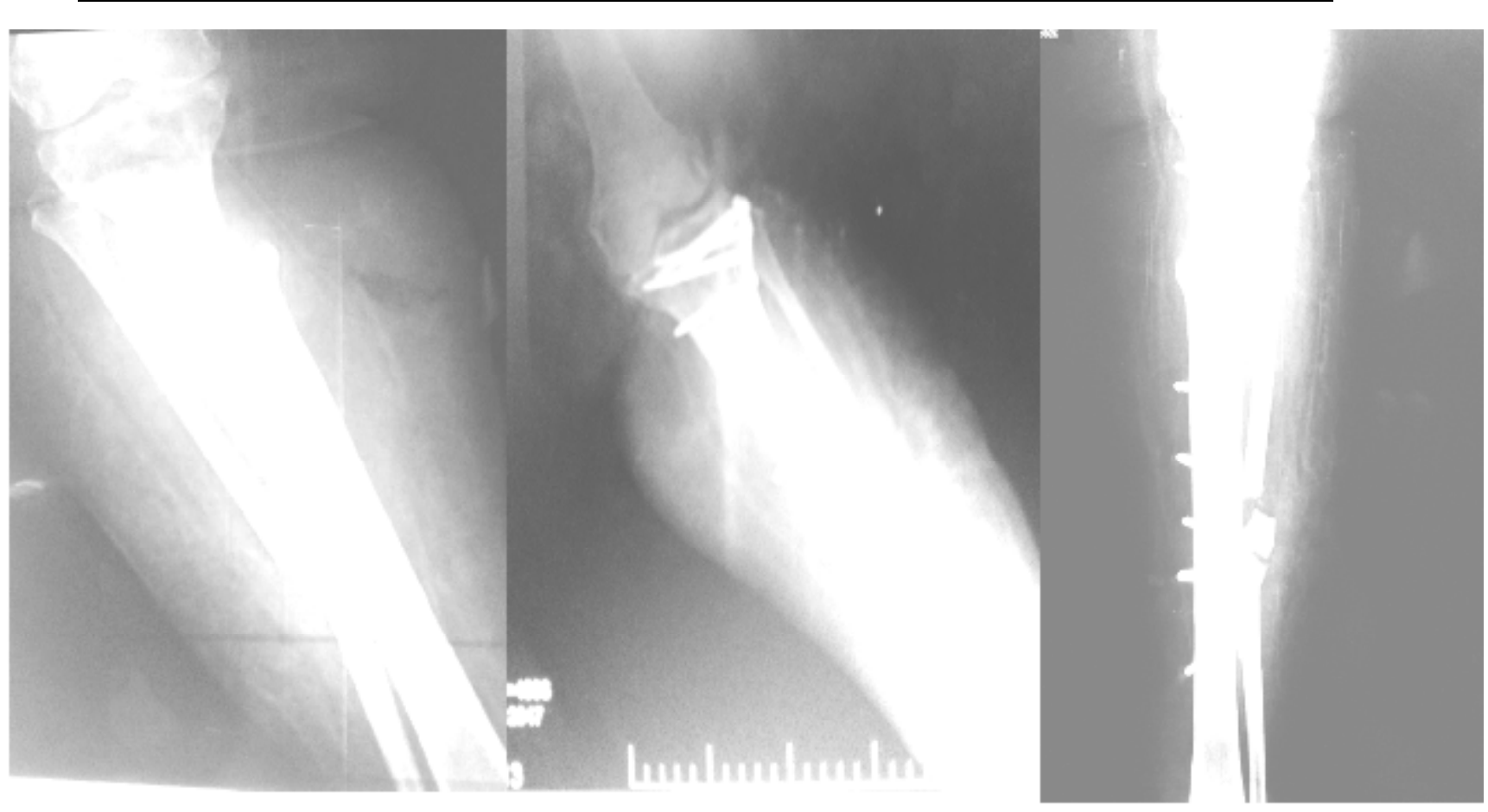

(A)

( B )

( C)

Female patient $\mathbf{5 5}$ years old presented by aspticnon union tibia managed by plating and grafting . (A) preoperative $\mathrm{x}$ ray . ( $\mathrm{B}$ ) postoperative $\mathrm{x}$ ray .

(C) five months follow up $x$ ray .

\section{References}

1. Boyd HB, Lipinsky SW, Willey JH. Observation on nonunion of the shafts of long bones with statistical analysis of $\mathbf{8 4 2}$ patients. J. Bone J. Surg. 1961; 43A: 159.

2- Weber, B.G.; Cech, O. Pseudarthrosis. Bern, Switzerland, Hans Huber, 1976.

3. Sledge SL, Johnson KD, Henley MB, Watson JT. Intramedullary nailing with reaming to treat nonunion oftibia. $\mathrm{J}$ Bone $\mathrm{J}$. Surg 1989; 71A: 1004.

4.Clancey GJ, Winquist RA, Hansen ST. Nonunion of the tibia treated with Kunt,cher intramedullary nailing. Clin.Orthop 1982; 167: 191.
5. Megas $\mathrm{P}$, Panagiotopoulos E, Skriviliotakis $\mathrm{S}$, Lambiris E. Intramedullary nailing in the treatment of

aseptic tibialnonunion. Injury 2001; 32: 23339.

6. OlerudC, Molander H. A scoring system for symptom evaluation after ankle fracture - Arch Orthop Trauma Surg. 1984;103:190-194.

7 .Weresh MJ, Hakanson R, Stover M, et al. Failure ofexchange reamed intramedullary nails for ununitedfemoral shaft fractures. $\mathbf{J}$ Orthop Trauma, 2000, 14: 335-338.

8- $\mathrm{CC} \mathrm{Wu}$. Reaming bone grafting to treat tibial shaft aseptic nonunion after plating . J Orthop Res 2003: 11(1): 16-21.

9- WI Faisham, MMed, A R Sulaiman ; et al . Early Outcome of Reamed Interlocking Nail for NonUnion of Tibia. Med $\mathbf{J}$ Malaysia Res 2006 Vol 61 No 3.

10.Galal Z. Said \& Mohammad M. ElSharkawi ; et al . Fibula-pro-tibia in plating 
SOHAG MEDICAL JOURNAL

Vol. 21 No.1 Jan 2017 tibial non-unions . J (SICOT) (2011) 35:1713-1718 .

11. Wu CC, Shih CH, Chen WJ, Tai CL. High success rate with exchanging to treat a tibial shaft aseptic non union .J Orthop Trauma 1999;13:33-8.
12.Devnani AS et; al. Simple approach to the management of aseptic non union of shaft of long bones. Singapore Med J 2001: 42 (1) :20-25. 